\title{
The relationship between hepatopulmonary syndrome and altitude
}

\author{
Morgan A Valley MS MPH${ }^{1}$, James F Trotter MD², Deborah Thomas PhD ${ }^{3,4,5}$, Adit A Ginde MD MPH ${ }^{4,6}$, \\ Steven R Lowenstein MD MPH ${ }^{4,6}$, Benjamin Honigman $\mathrm{MD}^{3,6}$
}

MA Valley, JF Trotter, D Thomas, AA Ginde, SR Lowenstein, B Honigman. The relationship between hepatopulmonary syndrome and altitude. Can J Gastroenterol Hepatol 2014;28(3):140-142.

BACKGROUND: In a previous small retrospective study, the authors reported that hepatopulmonary syndrome was less common among liver transplant candidates at high-altitude centres compared with low-altitude centres.

OBJECTIVE: To further explore the relationship between hepatopulmonary syndrome and altitude of residence in a larger patient cohort. METHODS: A cohort of 65,264 liver transplant candidates in the Organ Procurement and Transplantation Network liver database between 1988 and 2006 was analyzed. Hepatopulmonary syndrome diagnosis was determined during a comprehensive evaluation at a liver transplant centre by physicians who were experienced in the diagnosis and treatment of hepatopulmonary syndrome. The altitude of residence was determined for each patient by assigning the mean altitude of the zip code of residence at the time of entry on the wait list. Mean zip code elevation was calculated using the National Elevation Dataset of the United States Geological Survey, which provides exact elevation measurements across the entire country.

RESULTS: Hepatopulmonary syndrome was significantly less common at higher resident altitudes $(\mathrm{P}=0.015)$. After adjusting for age, sex and Model for End-Stage Liver Disease score, there was a $46 \%$ decrease in the odds of hepatopulmonary syndrome with every increase of $1000 \mathrm{~m}$ of resident elevation (OR 0.54 [95\% CI 0.33 to 0.89]).

CONCLUSION: There was a negative association between altitude and hepatopulmonary syndrome. One plausible explanation is that the lower ambient oxygen found at higher elevation leads to pulmonary vasoconstriction, which mitigates the primary physiological lesion of hepatopulmonary syndrome, namely, pulmonary vasodilation.

Key Words: Altitude medicine; Hepatopulmonary syndrome; Hypoxia; Liver transplantation

$\mathrm{H}$ epatopulmonary syndrome (HPS) is characterized by an oxygenation defect induced by pulmonary vascular dilation in patients with end-stage liver disease (1). Up to $20 \%$ of liver transplant candidates have HPS (2); once diagnosed, survival is significantly shorter compared with other liver transplant candidates (3). While several therapies, including pentoxyfylline, methylene blue and garlic have been evaluated, the only proven effective treatment for HPS is liver transplantation (4-7).

The hallmark of HPS is a defect in arterial oxygenation. In most patients with HPS, the primary disturbance is intrapulmonary vascular dilation, which primarily leads to marked ventilation-perfusion mismatch, with some contribution from right-to-left shunting and subsequent hypoxemia (1). In animal models of cirrhosis and HPS, there is increased hepatic production of endothelin, which in turn causes

\section{Le lien entre le syndrome hépatopulmonaire et l'altitude}

HISTORIQUE : Dans une petite étude rétrospective, les auteurs ont constaté que le syndrome hépatopulmonaire était moins courant chez les candidats à une transplantation hépatique des centres en haute altitude que chez ceux des centres à basse altitude.

OBJECTIF : Examiner de plus près le lien entre le syndrome hépatopulmonaire et l'altitude du lieu de résidence dans une cohorte de patients plus vaste.

MÉTHODOLOGIE : Les chercheurs ont analysé 65264 candidats à la transplantation hépatique inscrits dans la base de données hépatiques de l'Organ Procurement and Transplantation Network entre 1988 et 2006. Le diagnostic de syndrome hépatopulmonaire était posé dans le cadre d'une évaluation approfondie effectuée dans un centre de transplantation hépatique par des médecins habitués à diagnostiquer et à traiter ce syndrome. L'altitude de résidence de chaque patient était déterminée selon l'altitude moyenne du code postal de résidence au moment de l'inscription sur la liste d'attente. L'élévation moyenne du code postal était calculée au moyen des données nationales d'élévation de l'United States Geological Survey, qui fournit les mesures d'élévation exactes pour tout le pays.

RÉSULTATS : Le syndrome hépatopulmonaire était beaucoup plus rare lorsque le lieu de résidence se situait à haute altitude $(\mathrm{P}=0,015)$. Après rajustement compte tenu de l'âge, du sexe et de l'indice du modèle d'insuffisance hépatique terminale, on constatait une diminution de $46 \%$ du risque de syndrome hépatopulmonaire par tranche d'élévation du lieu de résidence de 1000 mètres (RRR 0,54 [95 \% IC $0,33$ à 0,89$]$ ).

CONCLUSION : La relation entre l'altitude et le syndrome hépatopulmonaire était inversement proportionnelle. Une explication plausible de ce phénomène serait que les taux d'oxygène ambiant plus faibles à haute altitude provoquent une vasoconstriction pulmonaire qui atténue la lésion physiologique primaire du syndrome hépatopulmonaire, c'est-à-dire la vasodilatation pulmonaire.

increased production of nitric oxide by endothelial cells in the pulmonary vasculature. This leads to relaxation of pulmonary vascular smooth muscle cells and pulmonary vasodilation (8). Animals with experimentally induced HPS also demonstrate increased levels of vascular endothelial-derived growth factor (9). Levels of another pulmonary vasodilator, carboxyhemoglobin, are also elevated in animal models and in individuals with HPS (10). Finally, oxygen in the associated alveoli cannot diffuse into the centre of the dilated alveolar capillary, leading to diffusion-perfusion impairment and impaired oxygenation.

Recently, it has been suggested that living at higher altitudes may protect against the development of HPS. In fact, in a small retrospective study, we found that, among end-stage liver disease patients awaiting transplantation, HPS was less prevalent in those treated at

${ }^{1}$ Department of Psychology, Colorado State University; ${ }^{2}$ Division of Gastroenterology and Hepatology, Baylor Health Care System; ${ }^{3}$ Altitude Research Center, University of Colorado Denver; ${ }^{4}$ Colorado School of Public Health; ${ }^{5}$ Department of Geography and Environmental Sciences, University of

Colorado Denver; ${ }^{6}$ Department of Emergency Medicine; University of Colorado School of Medicine, Denver, Colorado, USA

Correspondence: Ms Morgan A Valley, Colorado State University, 1876 Campus Delivery, Fort Collins, Colorado 80523, USA

Telephone 303-242-4808, e-mail morgan.valley@colostate.edu 
high-altitude transplant centres (Denver, Colorado, or Salt Lake City, Utah) compared with low-altitude centres (in North Carolina) (11). The hypoxia associated with living at moderate altitudes possibly enhances pulmonary vasoconstriction to a degree sufficient to protect patients against the vasodilation that causes HPS.

The present study sought to further explore the relationship between HPS and altitude by using geographical information systems (GIS). We collected information regarding duration and severity of liver disease, the presence of HPS and the altitude estimate of zip code residence for all patients with end-stage liver disease who were listed on the national Organ Procurement and Transplantation Network (OPTN) liver transplant wait list database. We hypothesized that higher altitude would be associated with a lower prevalence of HPS among American orthotopic liver transplant candidates.

\section{METHODS}

The present study was a retrospective analysis of the characteristics of 65,264 patients on the OPTN liver transplant wait list from 1988 to 2006. The diagnosis of HPS was determined by the treating physician and transplant centre.

Altitude, the primary predictor variable, was determined for each patient by assigning the mean altitude of the zip code of residence at the time of entry onto the OPTN wait list. Mean zip code elevation was calculated using the National Elevation Dataset produced by the United States Geological Survey, which provides elevation measures for $30 \mathrm{~m} \times 30 \mathrm{~m}$ geographical units across the entire United States (http://ned.usgs.gov/). National Elevation Dataset data were combined with zip code boundaries in GIS software, ESRI ArcGIS version 9.2, and calculated mean elevation for each zip code by averaging all of the $30 \mathrm{~m} \times 30 \mathrm{~m}$ units within that zip code. Altitude was successfully matched to $60,262(92.3 \%)$ patients on the wait list; these patients comprised the study group.

Additional covariates obtained from the OPTN database included age, sex and the raw Model for End-stage Liver Disease (MELD) score, an accepted measure of liver disease severity. MELD includes international normalized ratio, bilirubin and creatinine levels, and whether the patient underwent dialysis at least twice in the past week. While the MELD model was not adopted in the United States until February 2002, raw MELD scores were calculated for all participants based on their test scores.

Data analysis proceeded in three steps. First, demographic and clinical characteristics of the participants were summarized using means and SDs for measurement variables and proportions and 95\% CIs for categorical data. Second, $t$ tests and $\chi^{2}$ statistics were used to test for bivariate associations between the primary outcome (ie, HPS) and participant characteristics, including age, sex and MELD score. A binary logistic regression was conducted to test for an association between altitude (in metres) of residence and the prevalance of HPS. Third, multiple logistic regression was performed to test for an independent, statistically significant association between HPS and altitude (as a continuous variable), after adjusting for age, sex and MELD score.

Patients with more severe liver disease were suspected to live preferentially at lower altitudes (a 'migration effect'). An association between altitude of residence and MELD score was tested for by calculating Pearson's correlation coefficient.

The present study was determined to be exempt from review by the Colorado Multiple Institutional Review Board.

\section{RESULTS}

Of the 60,524 patients, $262(0.43 \%$ [95\% CI $0.39 \%$ to $0.49 \%$ ]) had a reported diagnosis of HPS. The majority $(60.5 \%)$ of the participants were male. The mean $( \pm \mathrm{SD})$ age of participants was $44.59 \pm 17.94$ years (range $<1$ year to 84 years). Participants had a mean MELD score of $16.7 \pm 8.44$ (range 6 to 77 ) and mean residence zip code altitude of $241.39 \pm 352.76 \mathrm{~m}$ (range $0 \mathrm{~m}$ to $3096 \mathrm{~m}$ ). The mean MELD score of participants with HPS was 2.1 points lower than those without HPS $(t=5.86 ; \mathrm{P}<0.001)$. There was no correlation between MELD scores
TABLE 1

The prevalence of hepatopulmonary syndrome (HPS) and altitude of residence

\begin{tabular}{lrrcc}
\hline Altitude, $\mathbf{m}$ & No HPS & HPS & \% HPS & 95\% Cl \\
\hline-2 to 250 & 41,653 & 198 & 0.47 & $0.41-0.55$ \\
251 to 500 & 13,923 & 53 & 0.38 & $0.29-0.50$ \\
501 to 750 & 1308 & 4 & 0.30 & $0.12-0.78$ \\
751 to 1000 & 624 & 0 & 0.00 & $0.00-0.61$ \\
1001 to 1500 & 998 & 4 & 0.40 & $0.16-1.03$ \\
1501 to 2000 & 1336 & 3 & 0.22 & $0.08-0.66$ \\
2001 to 2500 & 307 & 0 & 0.00 & $0.00-1.24$ \\
2501 to 3000 & 90 & 0 & 0.00 & $0.00-4.09$ \\
$\geq 3000$ & 23 & 0 & 0.00 & $0.00-14.31$ \\
Total & 60,262 & 262 & 0.43 & $0.39-0.49$ \\
\hline
\end{tabular}

and altitude (Pearson's $r=-0.005 ; P=0.27$ ), suggesting that the distribution of severe illness was similar at lower and higher altitudes.

Table 1 summarizes the prevalence rates of HPS at each successively higher altitude. The unadjusted logistic regression analysis showed that HPS was significantly less common at higher resident altitudes $(\mathrm{P}=0.015)$. No patient living above $2000 \mathrm{~m}$ had a diagnosis of HPS $(0.0 \%[95 \% \mathrm{CI} 0 \%$ to $0.91 \%])$. After adjusting for age, sex and MELD score, there was a $46 \%$ decrease in the odds of reporting HPS with every increase of $1000 \mathrm{~m}$ of resident elevation (OR 0.54 [95\% Cl 0.33 to 0.89$]$ ).

\section{DISCUSSION}

The present study revealed a strong, negative association between HPS and altitude. While the reasons for this observation are unknown, several possibilities exist. Although the pulmonary vascular dynamics are complex in cirrhotic patients, one plausible explanation is that the lower ambient oxygen concentration found at higher elevation leads to pulmonary vasoconstriction, which mitigates the primary physiological lesion of HPS (namely, pulmonary vasodilation). Evidence of increased pulmonary vasoconstriction exists among residents at moderate and high altitudes (12). In addition to residents living at altitude, travellers to altitude may also develop pulmonary hypertension due to pulmonary vasoconstriction. This is believed to occur when the alveolar partial pressure of oxygen is $<70 \mathrm{mmHg}$, which corresponds to an altitude of approximately $2000 \mathrm{~m}$, although lower altitudes can precipitate pulmonary vasoconstriction when anomalous pulmonary vessels are present (13).

An alternative explanation is a 'migration effect'; that is, patients with symptoms or signs of HPS may relocate from higher to lower altitudes to lessen the effects of hypoxia (14). However, we found that the distribution of severe illness in our study, as measured by MELD score, was similar at higher and lower elevations. Nevertheless, these data are cross-sectional, and cross-sectional data cannot establish a temporal sequence or causal relationship between altitude and prevention of HPS.

The prevalence of HPS in the present study $(0.43 \%)$ was lower than expected and what has been reported in other publications (2). This may be due to patients on the wait list who have subclinical HPS. The reasons for this is that there is no therapy for this condition and the severity of hypoxemia in many affected patients is minimal. We are unsure as to how this may have influenced our results.

The present study had several limitations. Most importantly, the OPTN dataset does not require treating physicians to adhere to strict diagnostic criteria before assigning a diagnosis of HPS; consensus regarding the definition of HPS was not achieved until 2004 (15). As a result, the definitions of HPS in the study cohort may have varied across transplant centres over time. In addition, we did not have access to physiological variables to ensure the diagnosis of HPS in our patients. However, each of the patients in the present study underwent a comprehensive evaluation at a liver transplant centre by 
physicians who were experienced with the diagnosis and treatment of HPS. Additionally, we did not have access to other important clinical covariates (for example, smoking status, alcohol consumption) that could influence the severity of liver disease and the relationship between altitude and HPS. Some additional limitations are inherent in the GIS methods used to assign altitudes of residence. For example, we used the mean zip code altitude at time of entry into the liver transplant wait list for each patient; however, we were unable to determine patients' length of exposure at each altitude. In addition, the mean altitude of a zip code may not represent the true altitude of residence for every patient.

\section{SUMMARY}

We report a lower prevalence of HPS in liver transplant candidates residing at high altitude, after considering demographic factors and severity of hepatic disease. These findings could further the understanding of HPS and its potential treatment. For example, if hypoxia-induced pulmonary vasoconstriction is protective in these patients, then therapies that specifically induce pulmonary vasoconstriction may prove to be effective.

AUTHOR CONTRIBUTIONS: All authors listed contributed sufficiently to the project to be included as authors, and all those who are qualified to be authors are listed in the author byline. MV participated in project design, acquisition of data, management and analysis of data, interpretation of data and preparation of the manuscript. JT participated in the

\section{REFERENCES}

1. Rodríguez-Roisin R, Krowka MJ. Hepatopulmonary syndrome a liver-induced lung vascular disorder. N Engl J Med 2008;358:2378-87.

2. Palma DT, Fallon MB. The hepatopulmonary syndrome. J Hepatol 2006;45:617-25.

3. Fallon MB, Krowka MJ, Brown RS, et al. Pulmonary Vascular Complications of Liver Disease Study Group. Impact of hepatopulmonary syndrome on quality of life and survival in liver transplant candidates. Gastroenterology 2008;135:1168-75.

4. Tanikella R, Philips GM, Faulk DK, Kawut SM, Fallon MB. Pilot study of pentoxifylline in hepatopulmonary syndrome. Liver Transpl 2008;14:1199-203.

5. Abrams GA, Fallon MB. Treatment of hepatopulmonary syndrome with Allium sativum L. (garlic): A pilot trial. J Clin Gastroenterol 1998;27:232-5.

6. Groneberg DA, Fischer A. Methylene blue improves the hepatopulmonary syndrome. Ann Intern Med 2001;135:380-1.

7. Almeida JA, Riordan SM, Liu J, et al. Deleterious effect of nitric oxide inhibition in chronic hepatopulmonary syndrome.

Eur J Gastroenterol Hepatol 2007;19:341-6.

8. Luo B, Tang L, Wang Z, et al. Cholangiocyte endothelin 1 and transforming growth factor betal production in rat experimental hepatopulmonary syndrome. Gastroenterology 2005;129:682-95. inception and design of the project and contributed to data interpretation and preparation of the manuscript. DT participated in project design, acquisition of data, management and analysis of data and interpretation of data. AG contributed to the analysis and interpretation of the data and preparation of the manuscript. SL contributed to the analysis and interpretation of the data and preparation of the manuscript. BH participated in the inception and design of the project and contributed to analysis and data interpretation.

FUNDING: AA is supported by grant KL2 RR025779 from the National Institutes of Health. SL is supported in part by grant number R49/ CCR811509 from the Centers for Disease Control and Prevention.

DISCLOSURES: The authors have no financial disclosures or conflicts of interest to declare. The contents of this article are solely the responsibility of the authors and do not necessarily represent the official views of the Centers for Disease Control and Prevention. This article has not been previously published and is not under consideration in the same or substantially similar form in any other peer-reviewed media. A related abstract of this work was presented as a poster at the 2009 local meeting, Epidemiology Exchange at University of Colorado Denver (October, 2009). To the best of the authors' knowledge, no conflict of interest, financial or other, exists. Dr Ginde is supported by grant KL2 RR025779 from the National Institutes of Health. Dr Lowenstein is supported in part by Grant Number R49/CCR811509 from the Centers for Disease Control and Prevention.

9. Zhang J, Luo B, Tang L, et al. Pulmonary angiogenesis in a rat model of hepatopulmonary syndrome. Gastroenterology 2009; 136:1070-80

10. Zhang J, Ling Y, Luo B, et al. Analysis of pulmonary heme oxygenase-1 and nitric oxide synthase alterations in experimental hepatopulmonary syndrome. Gastroenterology 2003;125:1441-51.

11. Trotter JF, Box T, Heneghan M, Shrestha R. Hepatopulmonary syndrome in transplant centres at different altitudes. Lancet 2001;358:336.

12. Cruz-Jibaja J, Banchero N, Sime F, Peñaloza D, Gamboa R, Marticorena E. Correlation between pulmonary artery pressure and level of altitude. Chest 1964;46:446-51.

13. Luks AM. Can patients with pulmonary hypertension travel to high altitude? HAMB 2009;10:215-9.

14. Regensteiner JF, Moore LG. Migration of the elderly from high altitudes in Colorado. JAMA 1985;253:3124-8.

15. Rodriguez-Roisin R, Krowka MJ, Hervé P, Fallon MB, on behalf of the ERS Task Force Pulmonary-Hepatic Vascular Disorders (PHD) Scientific Committee. Pulmonary-hepatic vascular disorders (PHD). Eur Respir J 2004;24:861-80. 


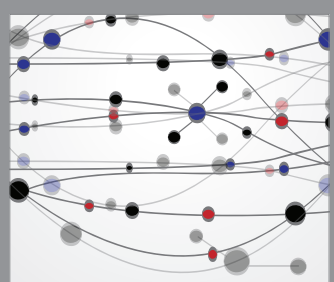

The Scientific World Journal
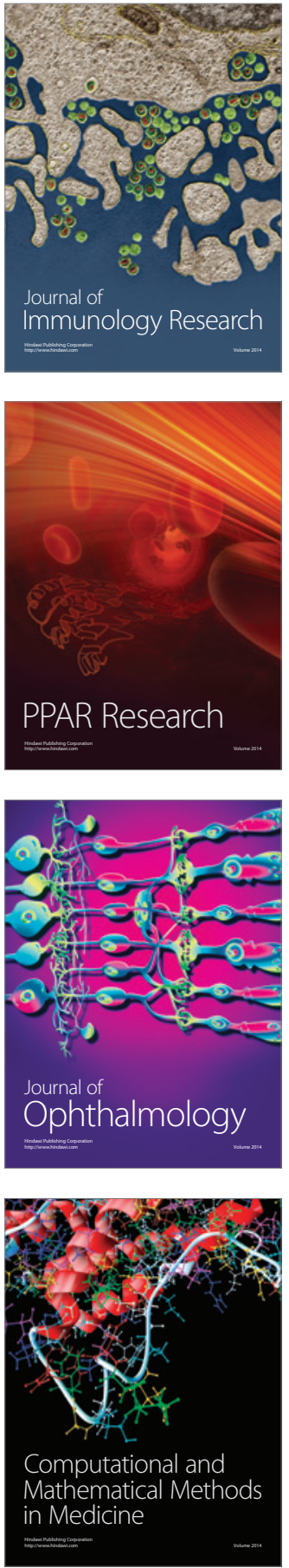

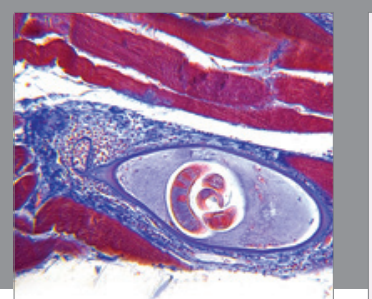

Gastroenterology Research and Practice

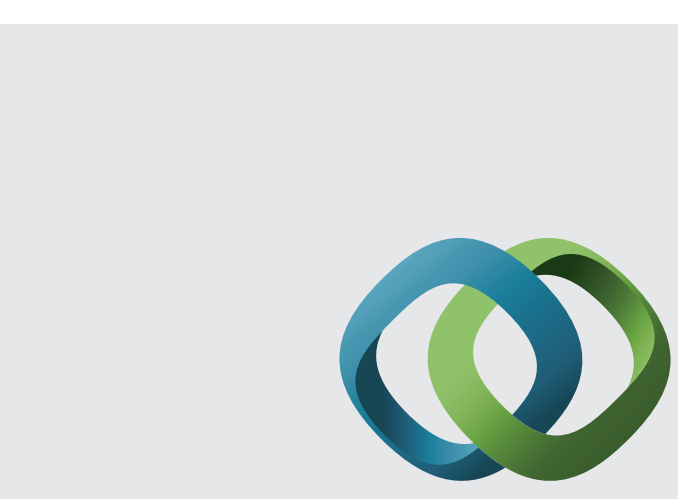

\section{Hindawi}

Submit your manuscripts at

http://www.hindawi.com
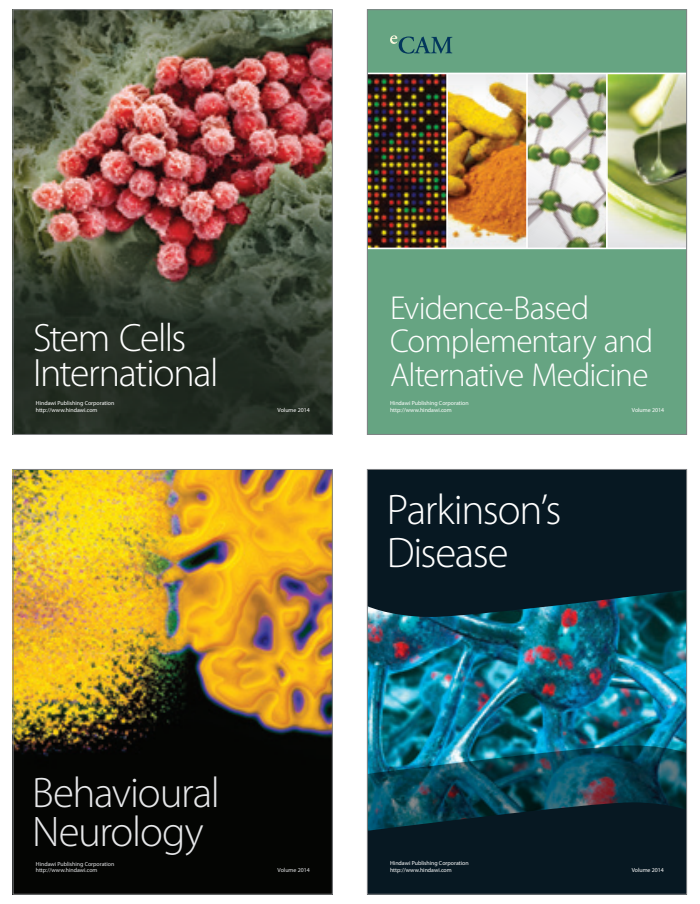
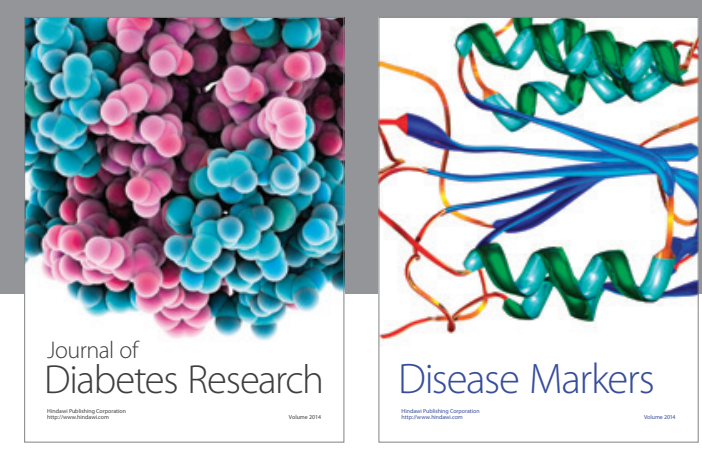

Disease Markers
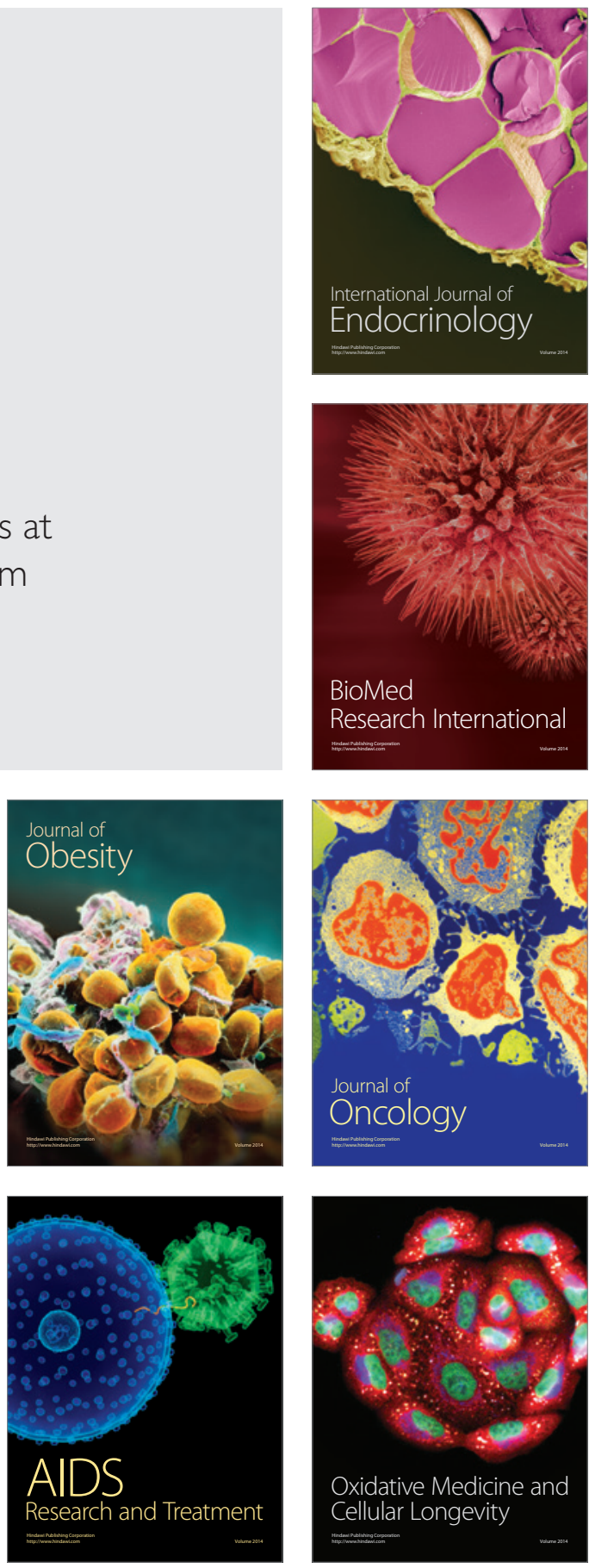